\title{
Are leaders leading the way with inclusion? Teachers' perceptions of systemic support and barriers towards inclusion
}

Abstract: This study explored teachers' views of systemic support for inclusion and barriers to its success at school and classroom levels. The research employed a thematic analysis of the insights of 120 Canadian primary and secondary teachers. Findings show that many key issues surrounding the success of inclusion lie not only at the level of the classroom teacher in terms of their attitude and practical application of inclusive strategies in the classroom, but that they also lie in the school climate and culture, and through systemic support from leadership and the Board. Major concerns were around human resource, other teachers' attitudes, competing demands, leadership and board support, and professional development. Results suggest the need for greater focus on high leverage, maximum impact systemic support at the leadership level if education systems are to truly make a paradigm shift towards inclusion.

Keywords: inclusion; systemic support; teacher attitudes; teacher concerns

\section{Introduction}

Inclusive education is a process of responding to diverse learner needs through modifications of the curriculum and changes to teaching delivery alongside the vision that it is the job of the mainstream school system to educate all children (UNESCO, 1994, 2005). It necessitates a switch in thinking from a medicalised individual deficit model to a model where teachers positively respond to all students' needs (Ainscow, 1999), with the focus not on fixing a problem but rather on enriching all learning. This change in focus though presents a significant challenge for teachers because inclusive education is now not only about disability but encompasses bigger issues such as educational reconstruction and school reform (Slee, 2003). This study explores how well teachers felt they are supported in this challenge.

Unfortunately, even though inclusive education is mandated in many countries by legislation (Author 1, a), and recommended by UNESCO, classroom teachers' endorsement of it is still often lukewarm (O'Rourke, 2015). Teacher response to inclusion has typically been studied by researching their use of inclusive classroom practices (e.g., Author 1, b; Ainscow, Booth, \& Dyson, 2006; McGhieRichmond, Underwood, \& Jordan, 2007), or attitudes towards inclusion (e.g., Brighton, 2003; Dyson, Farrell, Polat, Hutcheson \& Gallannaugh, 2004; Hastings \& Oakford, 2003; Lupart, Whitley, Odishaw, 
\& Macdonald, 2006; Mittler 2005; Sharma, Forlin, \& Loreman, 2008). There has however been less research focus on teachers' views of systemic support for inclusion within their own school context (e.g., McGhie-Richmond, Irvine, Loreman, Cizman, \& Lupart, 2013). This paper will explore the apparent paradox that although there is increased pre-service training and professional development to support inclusive teaching, and although Boards allocate funding, teachers often still feel they lack necessary skills, and that higher level support at school and district level is lacking. This paper examines two questions:

1. the extent to which teachers view there is systemic support for inclusion within their schools

2. teachers' views of barriers to inclusion at school and classroom level

\section{Literature review}

Since the 1994 Salamanca Statement (UNESCO, 1994) there has been a strong international policy focus upon the right of all students to learn within inclusive educational settings. In implementing these inclusion policies, schools need to provide support for teachers to learn new knowledge, skills, and understandings, as well as to gain access to specialist staff and other resources necessary to address diversity within today's classrooms (McGhie-Richmond et al., 2013).

\section{Professional learning for inclusive classrooms}

Major changes in training and values have therefore taken place in order to prepare teachers for more inclusive and diverse classrooms. More inclusive education subject content is apparent within pre-service training and professional development programmes (de Boer, Pijl, \& Minnaert, 2011; Forlin, Loreman, Sharma, \& Earle, 2009; Rose, 2001), in an attempt to transmit positive values towards successful inclusive educational practices (Ainscow, Booth, \& Dyson, 2006; de Boer et al., 2011; Rose, 2001; Sharma, Forlin, Loreman, \& Earle, 2006; Van Laarhoven, Munk, Lynch, Bosma, \& Rouse, 2007). Discussions about inclusion within schools can act as a mechanism to 
help teachers and administrators create a supportive culture, in particular one that problem-solves collaboratively, with shared values about diversity. These values then underlie what changes should be made in schools, as well as how and why such changes should be made in schools (Ainscow \& Sandill, 2010). However, there is concern about whether the support that teachers receive for inclusion is adequate (e.g., Glazzard, 2011; Idol, 2006; Loreman \& Deppeler, 2002). Many teachers continue to express apprehension with regard to their ability to teach inclusively, and often blame their professional development (Avramidis \& Kalyva, 2007; Bishop \& Jones, 2002; Lowrie, 2014; Schumm \& Vaughn, 1995; Winter, 2006), as well as inadequate pre-service training (Forlin, Keen, \& Barrett, 2008). Teacher professional development, often referred to as professional learning, can be considered a broad definition which includes both formal (such as qualifications; traditional workshops/programs) and informal modes of learning (such as learning from and with colleagues, and more lifelong learning approaches) (Hardy, 2012; Muijs, Day, Harris, \& Lindsey, 2004).

\section{Practicalities of implementing inclusive teaching in the classroom}

In addition to their concerns about lacking the necessary skills for inclusion, teachers have concerns about its practical implementation. For example, Horne and Timmons (2009) reported that while secondary teachers supported inclusion in principle, many were concerned about being able to implement it within their classrooms. Round, Subban, and Sharma's (2016) study of 158 Australian secondary school teachers similarly found that their participants were concerned that their schools were not adequately resourced to support effective inclusion. 'Resources' included human resources such as support staff, as well as physical resources and infrastructure to enable inclusion in the secondary context. It seems that teachers can hold positive perceptions towards the principle of inclusion yet feel negative about its practical implementation because of lack of resources, planning time, skills, prepared teaching materials, and specialist support (Avramidis, Bayliss, \& Burden, 2000; Chhabra, Srivastava, \& Srivastava, 2010; Chiner \& Cardona, 2013; Round et al., 2016). Furthermore, teachers may feel their ability to teach effectively, and manage their time to provide sufficient 
attention to all students in the class is challenged by focusing on students with special educational needs (Forlin, Keen \& Barrett, 2008; Lambe \& Bones, 2006).

\section{Systemic support for inclusion}

Some of these challenges cannot be remedied by more targeted professional development. This leads us beyond the level of teacher attitudes towards inclusion and classroom practices issues whose resolution lies at school or district level (Erten \& Savage, 2012; Sharma et al., 2008; Sokal \& Sharma, 2014). For example, some studies have suggested reports of under-funding as a persistent obstacle to successful inclusion (Glazzard, 2011; Idol, 2006; Loreman \& Deppeler, 2002). One of the key findings in Anderson, Klassen and Georgiou's (2007) study of 162 primary school teachers questioned was that they were highly concerned about severe time constraints when implementing inclusion, and that a proposed cut in budget would exacerbate this with a decrease in the number of teacher assistants and the availability of resources. Furthermore, as Sokal and Sharma state: "schoolbased budgetary decisions regarding scheduling teachers' release time to plan and meet about their students and the provision of adequate resources and materials to meet the needs of diverse learners are typically outside the teachers' decision-making power" $(2014, \mathrm{p} 66)$. Worryingly, there is evidence that negative attitudes towards inclusion due to these factors outside teacher control have also been associated with teacher stress, lower job satisfaction, and leaving the profession (Wang, Hall, \& Rahimi, 2015).

In Canada, where responsibilities within education often lie within each province a number of policies have been implemented which focus on inclusion. However, while the context of these policies are often framed around inclusion, the primary focus is often towards students with special educational needs and disabilities. Furthermore, within the province of Ontario, the challenge faced with engaging all students within an inclusive context under recent and present conditions, many of the recent policies still privilege students with special educational needs and disabilities in Ontario educational policies, with the main emphasis upon 'integrating' these students into 'regular classrooms' rather than classrooms being inclusive of all students (Hardy \& Woodcock, 2015). For 
example, the Closing the Gaps for students with Special Educational Needs in Ontario: Research and Trends and Capacity Building (Ministry of Education, 2009) states that "in Ontario, students with special educational needs are regularly placed into regular classrooms where they receive programs and services" (p. 17). In response to improving support and professional development for teachers around inclusion within schools and classrooms, 'additional qualifications' are governmentaccredited short-courses in specific educational areas such as special education. However, as some studies (such as Woodcock \& Hardy, 2017) have found, these additional qualifications in special education may not positively change teachers' attitudes, or beliefs about inclusive education.

While the inclusive learning environment is undoubtedly influenced by teachers' attitudes, beliefs, and actions, in order for these to be developed effectively, teachers also need to feel supported by the education systems that they work within (Ainscow \& Sandill, 2010). As well as focusing on teachers and their attitudes, beliefs, knowledge and skills, there is also then a need to focus on systemic changes that school leaders can make to support teachers and to change attitudes and develop necessary classroom skills.

\section{Theoretical underpinning}

This focus on systemic change can be carried out through what Senge (1990) called 'levers' as actions that can be taken to change the behaviour of the organisation and those within it. According to Senge, there are two types of leverages; low leverage points of action and high leverage points of action. Low leverage points of action attempt to solve intermediate causes with a great deal of effort but with little influence. For example, if someone was to try and move a car by pushing it manually it would entail a great deal of effort but the car would barely move. High leverage points of action attempt to solve deeper root causes to the problems with minimal effort and maximum impact. For example, if someone was to try and move a car by turning the engine on and using the accelerator the effort would be minimal but the car would move a great deal faster resulting in the action having a greater impact. Senge suggested that in educational settings low leverage points of action could include policy documents, conferences, and in-service courses. While 
these may make an impact they generally do not contribute to sweeping changes in education and so we should aim for higher leverage points of action through more subtle, less obvious actions.

It is these high points of leverage that place schools and educational leaders at the centre of the analysis. Senge's theoretical framework suggests therefore that support for teachers such as formal types of professional development and policy will likely only have minimal influence. Higher leverage support mechanisms from the School and District administration may be necessary for inclusion to happen successfully.

The current study endeavoured to investigate these higher leverage points of action, by exploring teachers' views of the systemic support within their schools and what they see as the most significant barriers to the success of inclusion at a whole school and classroom level. Furthermore, the above evidence of variability of policy and practice concerning inclusive education suggests that there is still considerable progress to be made by schools to provide more successful inclusive environments and this study endeavoured to explore what teachers' current concerns and barriers were to successful inclusion, as well as explore the extent to which systemic support is in place to help teachers teach more inclusively.

\section{Method}

This research is part of a larger dataset across three countries - Canada, England, Australia investigating teachers' current experiences and views of inclusion under current policy conditions The survey carried out comprised three sections: demographic information; a Likert-scale questionnaire to examining teachers' perceptions about inclusion, and; short-answer questions investigating systemic support through professional development, resources, and understanding and concerns about inclusion. This study draws on a survey of qualitative responses from 120 Canadian teachers (78 primary, 41 secondary, and 1 non-identified) from a random sample of schools in the greater metropolitan area of southern Ontario. Of the 120 Canadian teachers, $80 \%$ were female and $20 \%$ were male which was similar to the ratio of female to male teachers in Ontario (Ontario 
Ministry of Education, 2016). Moreover, of the 120 participating teachers, $4 \%$ were 25 years of age and under; $38 \%$ were between 26 and 35; 32\% were between 36 and 45; 20\% were between 46 and 55 ; and $6 \%$ were over 55 years of age. From the participating cohort of primary and secondary teachers in this study, $32 \%$ had been teaching for 5 years or less; $26 \%$ had been teaching for $6-10$ years; $28 \%$ had been teaching for $11-20$ years; and, $14 \%$ had been teaching for over 20 years. With regards to postgraduate qualifications, $15 \%$ of the participants had received a postgraduate diploma; $27 \%$ of the participants had completed a Masters degree; and, $1 \%$ had completed a Doctorate degree. Fifty-seven percent of the 120 participants did not have any postgraduate qualifications.

Ethical approval was obtained from the relevant university ethics committee and participating State/Educational Authority/ School Boards, and then permission was granted from school principals. Following this, teachers in schools where Principals had agreed were advised about the study in staff meetings and invited to participate. All responses were anonymous. A unique identification number was allocated to each respondent (T1, $\mathrm{T} 2$ etc.).

The aspect of the survey which this study drew upon focused on short-answer questions investigating teachers' systemic support through professional development, resources, and understanding and concerns about inclusion. The findings from this survey on teachers' understandings of inclusion and their beliefs about its effectiveness (Questions 1 and 2) have already been reported (Author 1, d) along with the professional development (Author 1, c).

The present study comprises a qualitative analysis of teachers' free text responses to survey Questions 4 and 6 respectively, where teachers were asked:

- Is there any systemic support for inclusion within your school?

- What are the most significant barriers to the success of inclusion at a school and classroom level?

Each written response to these two questions was imported into NVivo 11, a qualitative data analysis application that helps in data management. NVivo allows emerging themes to be easily 
categorised, contextualised, coded and recoded, and facilitates examination of links between concepts. Systematic analysis of these responses was carried out following Miles, Huberman and Saldaňa's (2014) coding guidelines for developing thematic conceptual matrix summaries of qualitative data. Responses were carefully read by Author 2 , with a view to drawing out sentences from the written text where respondents seemed to be making a point about systemic support or about barriers to successful inclusion. A code (or codes) was then allocated to this 'theme'. Using these coding procedures, themes were further coded into sub-themes. Additional coding was carried out to separate statements into 'positive' and 'negative'. Exemplar quotes for each theme and subtheme are provided in the tables below.

This thematic analysis involved an iterative process in which coding and recoding was carried out until all data were able to be classified within the thematic categories. In order to address the reliability of categorisation, Author 2's coding categories were then check-coded by Author 1. Intercoder reliability was $81 \%$. Joint agreement on final coding was reached through discussion. The use of this approach allowed themes and sub-themes to emerge from the data to help us understand the teachers' perceptions of systemic support and barriers that are currently in place with regard to inclusion in school. Findings were then summarised in matrices as suggested by Miles et al. (2014) in order to encapsulate rich qualitative data in a way that allows a complete summary of the full dataset. The intention is that patterns and themes can be seen in this ordered matrix, as easily as in a table of quantitative data. This also provides transparency of coding and provides the reader with evidence for categorisation. Numbers of respondents for each sub-theme have also been provided to give the reader a sense of which themes were most prevalent.

\section{Results}

Four conceptual themes emerged from the data through the coding process and form the four columns of the matrix (see Tables 1-4). These were: systemic support, specialist resources, managing class learning, and attitudes. These themes were further coded into sub-themes, with the 
number of responses within these themes included within each table. Positive and negative statements were further separated in each table providing exemplar quotes for each theme and subtheme. These exemplars provide a snapshot of the range and content of issues relevant to the teachers in the study within each sub-theme. Exemplars additional to those presented in each table have been incorporated in the text below to further illustrate themes. Figure 1 presents an overview of the number of positive and negative comments for each sub-theme. Negative comments have been interpreted as implying minimal impact, low leverage actions, and positive comments as higher leverage points of action with greater potential for influence. This will be developed in the discussion.

$<$ Insert Figure 1 $>$

\section{Systemic support}

Within the theme 'systemic support' were three sub-themes: 'leadership and board support', 'professional development', and 'budgets'. Most statements (27) within this theme came under the coding sub-theme category of 'leadership and board support'. These consisted of both positive and negative comments about board support (see Table 1). Positive comments were largely about the helpfulness of the board and administration in supporting inclusion. For example, T18 stated:

'the school is viewed as a community, and students, teachers, administrators and everyone else involved, works together to support the learning occurring in all aspects of the school'

However as can be seen from Table 1, some teachers felt a lack of support and proactive planning from leaders and administration, with problems only dealt with when they arose.

$<$ Insert Table 1 $>$ 
As Figure 1 shows, there were both positive and negative responses from 21 teachers on the role of 'professional development in supporting inclusion (see also Table 1).

'in-services, web-based information, PD [professional development] opportunities' (T11).

'too many expectations of teachers to do things outside of the classroom, and participate in 'meaningless' PD [professional development]' (T26).

Comments on budgets (13) were all negative (see Table 1), indicating lack of funding to fully support inclusion.

Thirteen respondents were unsure whether there was any systemic support for inclusion at their school. This response fell into two groups: one group was unaware of what systemic support meant within an inclusive environment; the other whether there was actually any systemic support for inclusion in their particular school.

\section{Specialist resources}

The largest group of teacher statements (56) across all themes and sub-themes reflected the importance of 'human' specialist resources for successful inclusion.

$<$ Insert Table 2>

Again, as Figure 1 shows, there were both positive and negative statements about this (see also Table 2).

'Our special education department tracks each student and makes ongoing suggestions to aid in their success' (T23).

'They will say yes, but it is all smoke and mirrors, the teachers are left alone to fend for themselves while the special education teachers file paperwork' (T63).

There were also nine comments about physical resources needed for inclusion, all of which were negative. 


\section{Managing class learning}

Thirty teachers were concerned with the challenge of competing demands in catering for student diversity within large classes. Their concerns here included addressing the educational, social and behavioural needs of everyone, feeling overwhelmed by increased demands and expectations.

'... handle disruptive behaviours and provide additional support to those students who need greater challenge, answers to their questions or encouragement' (T16).

Lack of time for planning and individualised instruction was raised in 22 responses (see Table 3).

'Teachers would need more planning time to better include all students. The workload of a classroom teacher is simply so large' (T59).

$<$ Insert Table 3>

There were thirteen responses about class size being a problem. Examples are provided in Table 3. There were 11 negative comments about the requirement to complete the curriculum within the school year alongside the task of modifying it for 'included' learners (see Table 3).

\section{Attitudes}

Under the theme 'attitudes' were sub-themes around 'other teachers', 'parent', 'peer' and 'included students' own attitudes to inclusion. 'Other teachers' attitudes reflected that even in schools that prided themselves on their inclusive practices, responsibility for inclusion was not uniformly shared by teachers across the school. As one teacher stated:

'not all staff embrace inclusion. Inclusion is selective in some of our classes. As a SERT [Special Education Resource Teacher] it has been difficult to initiate 
change when staff are unwilling to accept those students with needs as equals to those who do not have needs. That also means that participating in best practices of IEP [Individual Education Plan] development and implementation, and other strategies is selective' $(\mathrm{T} 70)^{1}$

Thus, rather than teachers' own attitudes, it was the attitudes of other teachers that seemed to be important.

'I personally believe that there aren't enough teachers who value inclusion. It is seen as more work for them, which they may not be open to' (T109).

Similarly, teachers' views of the attitudes of another group of 'others', that is to say parents, were also viewed as having a negative influence. All comments about parent attitudes were negative; their attitudes were viewed as a barrier to inclusion.

'Parents who don't feel/think the same way. It is hard to change some students' thinking if it is contrary to what is taught at home' (T111). 'parents who don't think there is anything wrong with their child' (T105).

Six teachers in the study also saw a third group of 'others' as providing a barrier to successful inclusion - the peer group of the child.

'Students' lack of information and maturity' (T36)

'Some students are reluctant to be inclusive of everyone and that can be a work in progress' (T106)

There were no positive statements about this.

Indeed, three teachers viewed the attitudes of included children themselves as a barrier.

'I find it frustrating at a classroom level that some students are unwilling to share with others their particular needs because I think that if everyone understood a little bit of the "why's" regarding behaviour inclusion would be somewhat easier' (T54).

\footnotetext{
${ }^{1}$ Number in brackets indicates teacher identification number.
} 
$<$ Insert Table 4>

As can be seen in Table 4, attitudes reported therefore reflected others' attitudes - other teachers, parents, peers, the included child, but teachers in the study did not seem to consider their own attitudes as barriers to, or supports for, successful inclusion.

\section{Discussion}

Comments from 120 Canadian teachers on supports and barriers for inclusion in their schools were coded into four themes, systemic support, specialist resources, managing class learning, and attitudes, and 14 sub-themes. Sub-themes which were of greatest concern to teachers, as indicated by the numbers of teachers responding in these categories were human resources, other teachers' attitudes, competing demands, leadership and board support, and professional development.

Human resources included 56 responses coded against this category which was the largest number for any single sub-theme. It should be noted that there were both positive and negative responses in this coding category, indicating that respondents valued the input of specialist staff such as the specialist education resource teachers, education assistants, psychologists, social workers and community nurses. Negative comments were all about the scarcity or lack of availability of these human resources in proportion to numbers of children. This resonates with previous findings (e.g., Avramidis et al., 2000; Chiner \& Cardona, 2013; Hastings \& Oakford, 2003; Round et al., 2016). This may also link to Author 1's findings where primary school principals reported that the teachers may rely on teacher aides and specialists to cater for students needing additional support, rather than seeing their classroom as an inclusive environment in itself (In press). It seems that little is changing in this perception over the years and that adequate resourcing for inclusive education is still an aspiration rather than a reality. Within the study's theoretical framework therefore, positive comments that valued effective human resource support mechanisms such as specialist staff, 
education assistants and other professional/paraprofessional staff supplied by the local school Board and District administrators may be viewed as higher leverage supports with high impact on inclusion (Senge, 1990).

Other teachers' attitudes received 34 comments all of which were negative. A key finding of our study was that the respondents seemed highly critical of the attitudes of other teachers as well as parents and students, rather than reflecting internally on their own attitudes and practices. It may be that respondents were contributing positively towards inclusion and that others were indeed not sufficiently playing their part. This supports the findings of other studies (such as Avramidis \& Norwich, 2002; Brighton, 2003; Dyson, et al., 2004; and Mittler, 2005) which found that teacher resistance and attitude towards inclusion were the most significant barriers to successful inclusion. Moreover, Dyson and colleagues (2004) found in their study that those schools that had better leadership resulting in more successful inclusion, led to school staff having a more positive attitude towards inclusion. Those schools that had difficulty problem-solving in inclusive contexts produced more problems for staff resulting in more negative attitudes. Furthermore, the present study found that the key concern regarding attitude towards inclusion was not directly the attitude of individual teachers themselves but the attitudes of their colleagues within the school. This was a key finding as the teachers in this study referred to one of the greatest concerns to successful inclusion being 'others'. If conceptualised through the lens of Weiner's (1985) attribution theory, respondents could be considered as using external attributions, attributing the failure of inclusion to factors external to themselves. It is worth noting then that teachers who used external attributions were less likely to make effective curricular adaptations (Author 2, a; Jordan, Kircaali-Iftar, \& Diamond, 1993; Wieman \& Welsh, 2015). Indeed external teacher attributions have also been associated with stress, lower job satisfaction, and leaving the profession (Wang et al., 2015). Eleven study respondents viewed attitudes of included students, or their parents as barriers to inclusion. In their Supporting Effective Teaching research studies, Jordan, Glenn, and McGhie-Richmond (2010) also found groups of teachers who blamed students and their families for students' lack of progress, as did Author 2. 
These negative attitudes, questioning other teachers' attitudes such as feeling as though they see inclusive teaching as more work, can be viewed as indicating low leverage actions that incur high effort, because they suggest having to work harder with increased demands. Reporting these as barriers indicates such effort has low impact on successful inclusion.

Competing demands had 30 comments. This may relate to 'other teachers' attitudes' towards inclusion above being perceived as negative because of professional challenges such as the competing demands of dealing with the whole class, time constraints, class size and the curriculum itself, all commonly acknowledged as barriers in previous studies (e.g., Anderson et al., 2007; Chiner \& Cardona, 2013; Florian, 2009; Giovagnoli et al., 2015; Horne \& Timmons, 2009; Rose, 2001). Indeed, it is worth noting that comments in these sub-themes, under the superordinate theme of managing class learning, were all negative reflecting that management of whole class learning is a concerning area for teachers in inclusive educational settings. As stated earlier in the paper, although inclusion is not new, many schools still struggle to implement it successfully. As Hosford and O'Sullivan (2016) found in their study, having a positive perception of school climate has a strong relationship to teachers' confidence in their ability to teach in inclusive classrooms. Furthermore, Hosford and O'Sullivan found that those who perceived a supportive climate through collaborative structures and resources held higher self-efficacious levels in relation to managing disruptive behaviour, implementing inclusive instruction and engaging in collaboration (2016). These findings around the competing demands are still major concerns towards inclusion which adds to the literature that has shown to be consistent over time which reflects the fact that while policies and professional development are changing, these so-called 'low leverage' activities may indeed only be changing the face and not the workings of inclusion.

Leadership and board support received 27 comments, both positive and negative. They reflected again issues of support by board administration and school leadership teams, with comments positive indicating where teachers felt supported, and negative where teachers felt support was lacking. These findings concur with Glazzard (2011), Idol (2006), and Loreman and 
Deppeler (2002) in that there is growing concern about whether the support that teachers receive for inclusion is adequate. However, as Author 1 found in their study of Australian primary school principals' perspective on inclusion, the principals constitute the 'problem' of inclusion to be associated with concerns about policy overload in practice, and funding (In press). The findings also show that these pressures around funding were also evident in the way some teachers justified 'shunting' students with disabilities out of their classroom, and onto specialists or teacher aides (with aides, ironically, construed as 'specialising' in responding to these students' needs) (Author 1, c). This links to our current findings on the comments on resources made by the teachers.

Professional development, mentioned by 21 teachers, is a concern that is consistent with other studies (e.g., de Boer et al., 2011; Horne \& Timmons, 2009; Rose, 2001). The relatively modest numbers in the present study who raised this point might suggest that the more practical support issues above now seemed more pressing. As the participants in this study stated, too often the professional development covers the principles of inclusion. However, more specific focus towards the practical application needs to be covered in order to support teachers. Furthermore, in Author 1's previous study (Author 1, c) on Canadian teachers' professional development they found that the more professional development that teachers had in special education (In Ontario - where this data was collected - the additional qualification in professional development is only offered in special education, not inclusion), the more detrimental attitude towards inclusion became. At the same time, those teachers who had not completed any formal professional development in special education and had learnt from 'on the job training' gained a more positive attitude towards inclusion. Thus, this formal professional development may be viewed as a low leverage point of action with low impact, while the informal, on the job, training was a higher leverage action resulting in greater impact. Similar to the findings from the present study, professional development needs to be implemented and used effectively if it is going to support teachers practically with inclusion. This also resonates with the issue of funding as lack of funding may not easily be resolved. Professional 
development in inclusive practice, however, needs to be considered as a cost-effective mechanism, and a high leverage point of action with minimum effort and maximum impact.

Taken together, negative statements about board support and leadership, and negative statements regarding the attitudes of other teachers, managing the whole class, and the importance of specialist staff suggests that teachers perhaps felt they were trying to manage inclusion on their own without adequate support from others, neither from their teacher colleagues, nor school leadership team, nor systemic support from the Board itself. Furthermore, these findings support the points raised by Ainscow and Sandill (2010) in that it is vital for teachers and school leaders to work together and support one another with new ideas and practices around inclusion if inclusion is to be successful. Future research is needed to explore the possible relationships between these themes and the importance of the cultural context for inclusion which research seems to be lacking.

The four main themes that emerged from this study, systemic support, specialist resources, managing class learning, and attitudes might be viewed within the broader heading of school climate, the common beliefs shared by school staff about practices and values (Author $2, b$ ). The teachers in the study from their different schools may be reflecting, and reflecting on, the culture around inclusion within their schools. The social climate of the school and its role in providing an effective educational environment for inclusion merits attention (Allodi, 2010; Author 2, b; Hosford \& O'Sullivan, 2016).

These findings raise important points as they indicate that many of the key issues surrounding the success of inclusion lie not only at the level of the teacher in terms of their attitudes of teachers and their practical application of inclusive strategies in the classroom, but that they also lie in the school climate and culture, and through systemic support from leadership and the Board. Key findings from this study were that attitudes from other teachers, human resources, competing demands, and professional development are all vital in order for inclusion to work. However, these are strongly influenced by school leadership and by the Board. Consequently, we recommend for inclusion to be more successful, the focus should not only be on low leverage points of action such 
as professional development but also in a more whole school high leverage approach where systemic support towards key issues such as competing demands, school climate and culture, including collaboration amongst staff and parents, can be addressed.

This raises the point about how local school boards, through schools, might guide the learning of the new insights, skills and ideas that teachers require for effective inclusive practices in their classrooms. While we necessarily prioritize what is best for all students, the only way to attain this student-centric focus is to understand the nature of teachers' learning and understanding, as well as needs through the systemic support that is put in place through local school boards and schools. Additional research needs to be undertaken into how leaders at school board and school level can adopt high leverage points of action to a greater extent to make maximum impact in supporting teachers in their beliefs and practices for inclusion. Further research also needs to be undertaken into the impact of leadership and board support towards inclusion and how this impacts on school culture and climate.

\section{Conclusion}

Over the last 30 years many countries have pushed through more inclusive school cultures preparing students for an inclusive society. Despite the benefits of inclusive education, there are still many challenges and barriers in addressing the needs of all students in an inclusive setting. The teachers in this Canadian sample have suggested a need for systemic support at leadership and board level to address key barriers to successful inclusion such as human and physical resources, attitudes of 'other' teachers, parents and students, as well as managing competing demands, time, class size and curriculum. Systemic supports can optimally focus on high leverage points of action where minimal effort results in maximum impact that addresses some of these barriers. Examination of positive and negative comments in this study suggests these are likely to be more effective in achieving inclusive pedagogies than low leverage actions. 


\section{References}

Ainscow, M. (1999). Understanding the development of inclusive schools. London: Falmer.

Ainscow, M., Booth, T., \& Dyson, A. (2006). Improving schools, developing inclusion. London: Routledge.

Ainscow, M., \& Sandill, A. (2010). Developing inclusive education systems: the role of organisational cultures and leadership. International Journal of Inclusive Education, 14(4), 401-416.

Allodi, M. W. (2010). The meaning of social climate of learning environments: Some reasons why we do not care enough about it. Learning Environments Research, 13(2), 89-104. doi:10.1007/s10984-010-9072-9

Anderson, C., Klassen, R., \& Georgiou, G. (2007). Inclusion in Australia: What teachers say they need and what school psychologists can offer. School Psychology International, 28(2), 131-147.

Author 1, a.

Author $1, b$.

Author 1, c.

Author 1, d.

Author 1, In Press.

Author 2, a.

Author 2, b.

Avramidis, E., Bayliss, P., \& Burden, R. (2000). Student teachers' attitudes towards the inclusion of children with special educational needs in the ordinary school. Teaching and Teacher Education, 16(3), 277-293. doi:http://dx.doi.org/10.1016/S0742-051X(99)00062-1 
Avramidis, E., \& Kalyva, (2007). The influence of teaching experience and professional development on Greek teachers' attitudes towards inclusion. European Journal of Special Needs Education, 22(4), 367-389

Avramadis, E., \& Norwich, B. (2002). Mainstream teachers' attitudes towards integration/inclusion: A review of the literature. European Journal of Special Needs Education, 17(2), 1-19.

Bishop, A., \& Jones, P. (2002). Promoting inclusive practice in primary initial teacher training: Influencing hearts as well as minds. Support for Learning, 17(2), 58-63

Brighton, C. (2003). The effects of middle schoolteachers' beliefs on classroom practices. Journal for the education of the Gifted, 27(3), 177-206.

Chhabra, S., Srivastava, R., \& Srivastava, I. (2010). Inclusive education in Botswana: The perceptions of school teachers. Journal of Disability Policy Studies, 20, 219-228.

Chiner, E., \& Cardona, M. C. (2013). Inclusive education in Spain: how do skills, resources, and supports affect regular education teachers' perceptions of inclusion? International Journal of Inclusive Education, 17(5), 526-541. doi:10.1080/13603116.2012.689864

de Boer, A., Pijl, S. J., \& Minnaert, A. (2011). Regular primary schoolteachers' attitudes towards inclusive education: a review of the literature. International Journal of Inclusive Education, 15(3), 331-353. doi:10.1080/13603110903030089

Dyson, A., Farrell, P., Polat, F., Hutcheson, G., \& Gallannaugh, F. (2004). Inclusion and pupil achievement (Research Report No: RR578). London, UK: Department for Education and Skills.

Erten, O., \& Savage, R. (2012). Moving forward in inclusive education research. International Journal of Inclusive Education, 16(2), 221-233.

Florian, L. (2009). Preparing teachers to work in 'schools for all'. Teaching and Teacher Education, 25(4), 533-534. doi:http://dx.doi.org/10.1016/j.tate.2009.02.004 
Forlin, C., Keen, M., \& Barrett, E. (2008). The concerns of mainstream teachers: Coping with inclusivity in an Australian context. International Journal of Disability, Development and Education, 55(3), 251-264.

Forlin, C., Loreman, T., Sharma, U., \& Earle, C. (2009). Demographic differences in changing preservice teachers' attitudes, sentiments and concerns about inclusive education. International Journal of Inclusive Education, 13(2), 195-209

Giovagnoli, G., Postorino, V., Fatta, L. M., Sanges, V., De Peppo, L., Vassena, L., . . Mazzone, L. (2015). Behavioral and emotional profile and parental stress in preschool children with autism spectrum disorder. Research in Developmental Disabilities, 45-46, 411-421.

Glazzard, J. (2011). Perceptions of the barriers to effective inclusion in one primary school: voices of teachers and teaching assistants. Support for Learning, 26(2), 56-63.

Hardy, I. (2012). The politics of teacher professional development: policy, research and practice. New York: Routledge.

Hastings, R., \& Oakford, S. (2003). Student teachers' attitudes towards the inclusion of children with special needs. Educational Psychology, 23(1), 87-94.

Horne, P. E., \& Timmons, V. (2009). Making it work: teachers' perspectives on inclusion. International Journal of Inclusive Education, 13(3), 273-286. doi:10.1080/13603110701433964

Hosford, S., \& O'Sullivan, S. (2016). A climate for self-efficacy: the relationship between school climate and teacher efficacy for inclusion. International Journal of Inclusive Education, 20(6), 604-621.

Idol, L. (2006). Toward inclusion of special education students in general education. Remedial and Special Education, 27(2), 77-94

Jordan, A., Glenn, C., \& McGhie-Richmond, D. (2010). The Supporting Effective Teaching (SET) project: The relationship of inclusive teaching practices to teachers' beliefs about disability 
and ability, and about their roles as teachers. Teaching and Teacher Education, 26(2), 259-266. doi:http://dx.doi.org/10.1016/j.tate.2009.03.005

Jordan, A., Kircaali-Iftar, G., \& Diamond, C. T. P. (1993). Who has a problem, the student or the teacher? Differences in teachers' beliefs about their work with at-risk and integrated exceptional students. International Journal of Disability, Development and Education, 40(1), 45-62. doi:10.1080/0156655930400104

Lambe, J., \& Bones, R. (2006). Student teachers' perceptions about inclusive classroom teaching in Northern Ireland prior to teaching practice experience. European Journal of Special Needs Education, 22(2), 167-186.

Loreman, T., \& Deppeler, J. (2002). Working towards full inclusion in education. The national issues. Journal for People with a Disability, 3(6), 5-8.

Lowrie, T. (2014). An educational practices framework: The potential for empowerment of the teaching profession. Journal of Education for Teaching, 40(1), 34-46.

Lupart, J., Whitley, J., Odishaw, J., \& McDonald, L. (2006). Whole school evaluation and inclusion: How elementary school participants perceive their learning community. In C. Dionne \& N. Rousseau (Eds). Transformation of educational practices: Research on inclusive education (pp. 113-143). Quebec: Presses de I'Universite du Quebec.

McGhie-Richmond, D., Irvine, A., Loreman, T., Cizman, J., \& Lupart, J. (2013). Teacher perspectives on inclusive education in rural Alberta, Canada. Canadian Journal of Education, 36(1), 195-239.

McGhie-Richmond, D., Underwood, K., \& Jordan, A. (2007). Developing effective instructional strategies for teaching in inclusive classrooms. Exceptionality Education Canada, 17(1), 27-51.

Miles, M., Huberman, M., \& Saldaňa, J. (2014). Qualitative data analysis: A methods sourcebook. Third edition. Thousand Oaks, CA: Sage. 
Mittler, P. (2005). Building bridges between special and mainstream services. Asian Pacific Disability Rehabilitation Journal, 16(1), 3-15.

Muijs, D., Day, C., Harris, A., \& Lindsay, G. (2004). Evaluating CPD: An overview. In C. Day, \& J. Sachs (Eds.), International handbook on the continuing professional development of teachers (pp. 291-310).Milton Keynes: Open University Press.

Ontario Ministry of Education. (2016). Quick Facts: Ontario Schools, 2013-2014.

http://www.edu.gov.on.ca/eng/general/elemsec/quickfacts/2013 2014.html, Accessed: 19/12/2017.

O'Rourke, J. (2015) Inclusive schooling: if it's so good - why is it so hard to sell? International Journal of Inclusive Education, 19(5), 530-546

Rose, R. (2001). Primary school teacher perceptions of the conditions required to include pupils with special educational needs. Educational Review, 53(2), 147-156.

doi:10.1080/00131910120055570

Round, R., Subban, P., \& Sharma, U. (2016). 'I don't have time to be this busy.' Exploring the concerns of secondary school teachers towards inclusive education. International Journal of Inclusive Education, 20(2), 185-198.

Schumm, J.S., \& Vaughn, S. (1995). Getting ready for inclusion: Is the stage set? Learning Disabilities Research and Practice, 10(3), 169-179.

Senge, P. (1990). The fifth discipline: the art and practice of the learning organization. New York, Doubleday/Currency.

Sharma, U., Forlin, C., \& Loreman, T. (2008). Impact of training on pre-service teachers' attitudes and concerns about inclusive education and sentiments about persons with disabilities. Disability and Society, 23(7), 773-785. 
Sharma, U., Forlin, C., Loreman, T., \& Earl, C. (2006). Pre-service teachers' attitudes, concerns and sentiments about inclusive education: An international comparison of novice pre-service teachers. International Journal of Special Education, 21(2), 80-93.

Slee, R. (2003). Inclusive education: A framework reform. In Inclusive education: A framework for reform pp 58-67 (Eds. V. Heung \& M. Ainscow). Hong Kong: Hong Kong Institute of Education.

Slee, R. (2011). The irregular school: Exclusion, schooling and inclusive education. Abingdon: Routledge.

Sokal, L., \& Sharma, U. (2014). Canadian in-service teachers' concerns, efficacy, and attitudes about inclusive teaching. Exceptionality Education International, 23, 59-71.

UNESCO(1994). Salamanca statement and framework for action on special needs education. Paris: UNESCO-Special Education, Division of Basic Education.

UNESCO (2005). Guidelines for inclusion: Ensuring access to education for all. Paris: UNESCO.

Van Laarhoven, T., Munk, D., Lynch, K., Bosma, J., \& Rouse, J. (2007). A model for preparing special and general education pre-service teachers for inclusive education. Journal of Teacher Education, 58(5), 440-455.

Wang, H., Hall, N. C., \& Rahimi, S. (2015). Self-efficacy and causal attributions in teachers: Effects on burnout, job satisfaction, illness, and quitting intentions. Teaching and Teacher Education, 47, 120-130. doi:http://dx.doi.org/10.1016/j.tate.2014.12.005

Weiner, B. (1985). An attributional theory of achievement motivation and emotion. Psychological Review, 92(4), 548-573.

Wieman, C., \& Welsh, A. (2015). The connection between teaching methods and attribution errors. Educational Psychology Review, 1-4. doi:10.1007/s10648-015-9317-3

Winter, E.C. (2006). Preparing new teachers for inclusive schools and classrooms. Support for Learning, 21(2), 85-91 